\title{
Identifying geographical patterns of wildfire orientation: A watershed-based analysis
}

\author{
Ana M.G. Barros ${ }^{\mathrm{a}, *}$, José M.C. Pereira ${ }^{\mathrm{a}}$, Ulric J. Lund ${ }^{\mathrm{b}}$ \\ ${ }^{a}$ Forest Research Centre, School of Agriculture, Technical University of Lisbon, Portugal \\ ${ }^{\mathrm{b}}$ Department of Statistics, California Polytechnic State University, United States
}

\section{A R T I C L E I N F O}

\section{Article history:}

Received 6 July 2011

Received in revised form 26 August 2011

Accepted 19 September 2011

\section{Keywords:}

Fire orientation

Orographic channelling

Watershed

Portugal

Circular statistics

\begin{abstract}
A B S T R A C T
We searched for geographical patterns in the orientation of wildfires, using watersheds as spatial support for the analysis. An 1975-2005 annual fire atlas of mainland Portugal was used to compute the orientation of fire perimeters and watersheds, using principal component analysis. Circular statistics were employed to test for the existence of a preferred, as opposed to random, mean fire orientation in each watershed, and to search for evidence of orographic channelling of fire by comparing fire orientation and watershed orientation. We also tested for differences in fire orientation patterns under conditions of mild versus severe fire weather. Our findings show that in the 31 year period of the study, $84 \%$ of the overall area burned is accounted for by watersheds where fires display preferential orientation. Twelve of 102 watersheds display evidence of alignment between fire and watershed orientation and we found no distinction in fire orientation as response to fire weather. The spatial arrangement of watersheds where fires present similar orientation suggests wind as a major driver of the broader patterns found in this study. Results from this analysis ought to be relevant for supporting the delineation of landscape-scale fuelbreaks.
\end{abstract}

(c) 2011 Elsevier B.V. All rights reserved.

\section{Introduction}

During the 1980-2004 period, wildfires in Portugal burned the equivalent of $30 \%$ of the area of the country, an incidence about three times higher than that recorded for neighboring Spain and Italy (Pereira et al., 2006). Large fires, by the standards of temperate, developed countries, are a feature of the contemporary fire regime in Portugal. Over 40 fires larger than 1000 hectares occurred in the summer of 1991, and more recently in 2003 and 2005, several fires exceeded 10,000 hectares. A 50,000+ hectares fire in central-eastern Portugal, which occurred under the extreme heat wave of 2003 (Trigo et al., 2006), was possibly the largest fire on record in southern Europe during the last 40 years.

Concerns with the social, economic and environmental consequences of large wildfires led to the development of a National Plan for Forest Protection Against Wildfires (AFN, 2006), which recommended a range of landscape and stand level, fuel management practices. These recommendations offer general guidelines for size, placement and maintenance of fuel treatments to be applied nationwide, but reinforce the need for site-specific analyses to be incorporated in regional implementation, sustaining the idea there

\footnotetext{
* Corresponding author. Address: Departamento do Recursos Naturais, Ambiente e Território, Instituto Superior de Agronomia, Tapada da Ajuda, 1349-017 Lisboa, Portugal. Tel.: +351 213653387; fax: +351 213653338.

E-mail address: barros.anamg@gmail.com (A.M.G. Barros).
}

is no such thing as a "one size fits all" in fuel treatment design (CNR, 2005; Reinhardt et al., 2008; Syphard et al., 2011).

Fuel treatments at landscape scale have the primary objective of reducing the risk of large, high intensity wildfires with devastating effects, while enhancing supression efforts (Weatherspoon and Skinner, 1996; Agee and Skinner, 2005; Reinhardt et al., 2008; Syphard et al., 2011). Moving from stand to landscape scale bears the underlying assumption that strategically placed treatment areas can modify fire behavior for the entire landscape (Collins et al., 2010).

Conceptual modeling shows that the greatest reduction in fire spread and intensity occurs when fuel treatments intersect head fire spread (Finney, 2001, 2004; Finney et al., 2007; Schmidt et al., 2008), confirming the topological inefficiency of random pattern fuel treatments (Loehle, 2004; Finney et al., 2007; Schmidt et al., 2008). Finney et al. (2007) showed that long-term landscape treatment effects on fire growth and behavior, in the western US, are primarily dependent on the rate of application and spatial pattern of treatment units. Schmidt et al. (2008) showed the efficiency of dispersed, strategically arranged treatments in reducing fire spread and area burned, particularly in simulations of high intensity fire. Finney et al. (2007) also showed that placement of fuel treatments intersecting spread direction, would require half the area treated than random treatments, to produce the same reduction in fire growth and behavior. The orientation of optimized treatment units in that study was determined using a fire growth 
simulation technique to identify major fire travel routes (Finney, 2001). Fire growth was simulated under specified weather conditions characterized by fuel moisture, wind speed and direction, obtained from historical records of climatology associated with severe fire events (Finney, 2001). Typically, this results in orientation of treatment units perpendicular to major fire spread movement, because heading fire behavior is more important to modify than flanking or backing portions (Finney, 2007). This suggests that research on the geographical orientation of fires is useful for fire management, assuming that the orientation of fire perimeters reveals the combined effects of wind and topography on fire spread patterns, and allows inference on heading fire movement. Systematic fire mapping over a time frame adequate for fire regime characterization can provide useful information for landscape-scale planning of fuel treatments, by establishing an historical pattern of spread orientation.

A few studies have addressed the issue of fire orientation in relation to weather patterns and topography. Parisien et al. (2006) found that the geographic orientation of fires was highly variable within and among Canadian ecozones, responding to the spatial variability of meteorological conditions. The main trends in fire direction across and within ecozones can be attributed not only to dominant weather patterns, but also to specific synoptic patterns associated with high fire danger. Throughout Canada, prevailing winds are generally from the west, and south-west winds dominate behind drying high pressure systems, often associated with increasing fire danger. As a consequence, nine out of the 10 ecozones had the highest fire bearing class frequency from west to east or southwest to northeast (Parisien et al., 2006).

Bergeron et al. (2004) analyzed the main direction of fire spread in northwestern Quebec's black spruce forest, and showed that most of the distance covered by fires occurred in the northwestsoutheast direction, although the frequency of occurrence of this direction was not high compared to the other directions. Also, those were larger fires, with a mean spread distance of $14.8 \mathrm{~km}$ (Bergeron et al., 2004).

Haydon et al. (2000) analyzed orientations of 196 fire "tongues”, more commonly known as fire fingers, extracted from 224 grassland fires in the Great Victoria Desert, Australia, and found good correspondence between prevailing wind direction and "tongue" orientation.
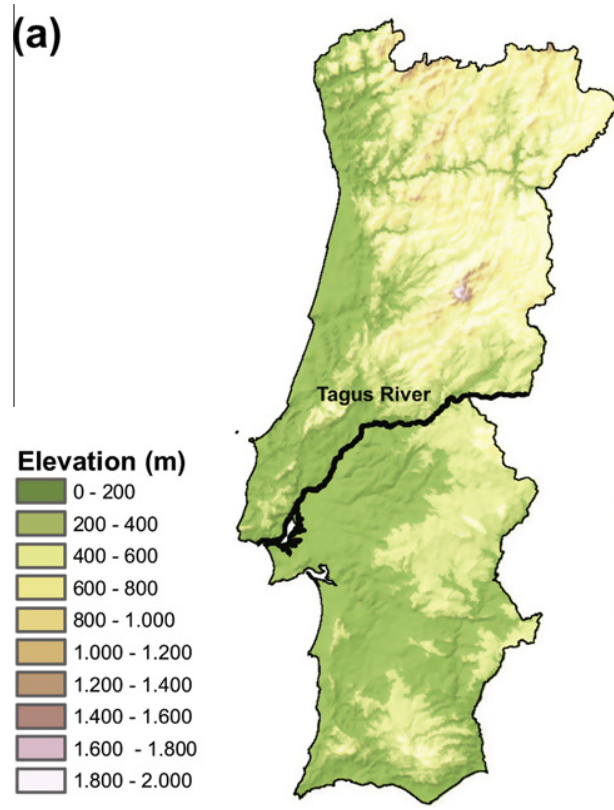

(b)

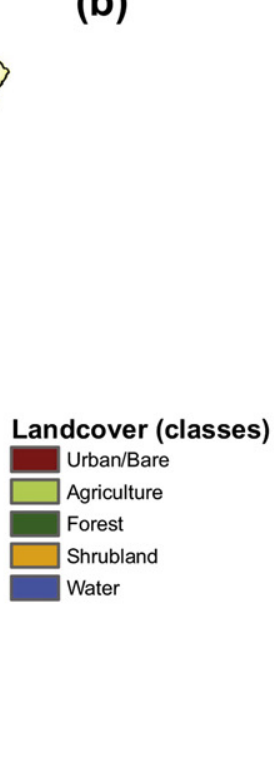

The main objective of this study was to determine whether fires display a preferred, as opposed to random orientation, at landscape scale. Secondary objectives were to determine if preferred fire orientation, when present, varies as a function of fire weather severity and to search for evidence of orographic wind channelling on fire orientation. We used principal component analysis to compute the orientation of fire and watershed perimeters following the methods developed by Luo (1998). A sequence of hypothesis tests for circular data were applied to establish preferential alignment of fire perimeter orientation in each watershed and for (1) comparing fire orientation between years with area burned above and below the mean annual value for the study period and (2) comparing fire orientation between small ( $\leqslant 100$ hectares) and large fires $(\geqslant 1000$ hectares) (Fisher, 1993). Orographic channelling was evaluated according to three different criteria: (1) by comparing a watershed's orientation with the $95 \%$ confidence interval of the mean fire perimeter orientation, (2) by comparing mean fire perimeter orientation with an interval within $\pm 15^{\circ}$ of watershed orientation, and (3) by computing circular-circular correlation between watershed and mean fire perimeter orientation (Fisher, 1993).

\section{Methods}

\subsection{Study area}

The study area is mainland Portugal, covering around 89,000 $\mathrm{km}^{2}$, located in the Iberian Peninsula, southwestern Europe (Fig. 1). It exhibits sharp topographic contrasts and can be roughly divided into two distinct regions, north and south of the Tagus river (Fig. 1). The region north of the Tagus river is dominated by a complex arrangement of mountains and highlands above $800 \mathrm{~m}$, interspersed by sharp valleys and pronounced depressions. South of the Tagus river valley is dominated by gentle rolling hills and plains and altitude is seldom higher than $600 \mathrm{~m}$, except for the mountains at the southwestern end (Ribeiro et al., 1987).

According to Koppen's classification, Portugal's mainland climate is classified into two distinct types of warm temperate climates with a dry season in the summer (Strahler and Strahler, 1992). North of the Tagus river and throughout the southern coast, the mean of the warmest month is below $22^{\circ} \mathrm{C}(\mathrm{Csb})$, while south of the Tagus river the warmest month mean temperature is above

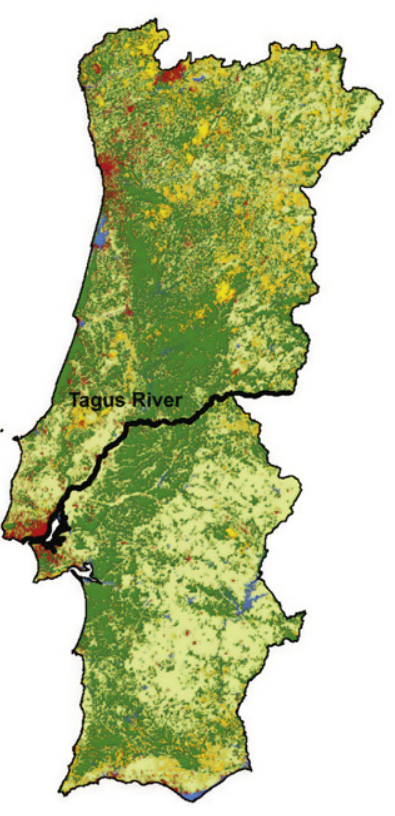

(c)

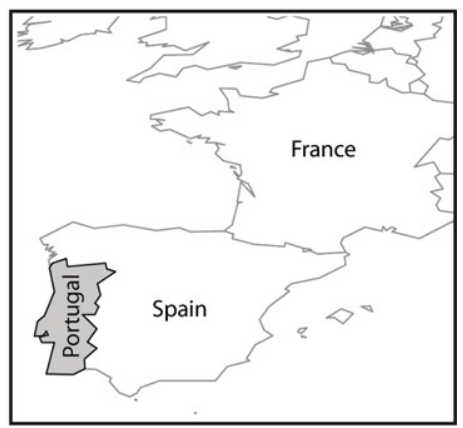

Fig. 1. Map of the study area, mainland Portugal, elevation (a), land cover classification (b) and location in Iberian Peninsula, southwestern Europe (c). 
$22{ }^{\circ} \mathrm{C}$ (Csa) (Strahler and Strahler, 1992). Mean annual precipitation is around $900 \mathrm{~mm}$ and spatially variable, with highest values being recorded in the highlands of the northwest region and lowest values in the southern and eastern regions of the territory (Miranda et al., 2002). Precipitation is distributed unevenly throughout the seasons, with the summer season (June to August) recording the lowest values of precipitation, corresponding to only $6 \%$ of the annual precipitation (Miranda et al., 2002).

Forests of mostly evergreen species and woodlands cover nearly $60 \%$ of the study area (AFN, 2007). The natural vegetation is pyrophytic and resistant to drought. The most important tree species are maritime pine (Pinus pinaster) in the northern half of the country, and blue gum (Eucalyptus globulus) along the western half of the country, as well as in a few areas in the eastern central region of the country (Fig. 1).

Land cover in southern Portugal is dominated by evergreen oak woodlands, managed as agro-forestry systems. Agricultural areas occupy about half of the study area and mostly dominate in the central coastal plain, along main river valleys, and in the southern part of the country. In central and northern Portugal, land ownership is very fragmented, and the agricultural landscape is a fine-grained mosaic of small parcels of diverse crops, vineyards, and olive groves. The agricultural landscapes of southern Portugal are more extensive and homogeneous, dominated by dryland farming of cereal crops. Most shrublands are found in eastern Portugal, but also occur in other parts of the country, usually in mountainous and sparsely populated regions (Fig. 1).

Fire incidence is higher in the northern half of the country, where the typical Mediterranean summer coexists with high net primary productivity, leading to an abundance of available fuels. Most of the area burned in Portugal (80\%) is due to fire events occurring during a small number (10\%) of summer days, under a typical atmospheric circulation pattern dominated by a strong ridge located over the Iberian Peninsula (Pereira et al., 2005). Carvalho et al. (2008) investigated the relationship between fire weather, the Canadian Fire Weather Index System and the area burned for 11 Portuguese districts, representing $66 \%$ of the total area burned between 1980 and 2004. Results suggested that fire weather explains the majority (80.9\%) of the variance of the area burned.

Fire history data were obtained from the Instituto Superior de Agronomia national fire atlas, based on late summer/fall Landsat imagery, covering the period from 1975 to 2005, on an annual basis. During the period used in this study, the fire atlas includes 34,345 fire perimeters, accounting for a total area burned of $3,670,000$ hectares. The mean annual area burned is 118,000 hectares, with a minimum of 15,500 hectares in 1997 , and a maximum of 440,400 hectares in 2003.

\subsection{Watershed delineation}

Watershed delineation was based on the $90 \mathrm{~m}$ digital terrain data from the Shuttle Radar Topography Mission (Farr et al., 2007), and the number and size of watersheds was determined iteratively with two goals: to obtain a detailed topographicallybased partitioning of the region, and to ensure that each watershed contained a minimum of 25 fires (Fisher, 1993).

Watersheds were delineated automatically in ArcMap 9.2 (ESRI, 2009), using a minimum area criterion. In the first iteration, minimum watershed area was set at 10,000 hectares, yielding a highly detailed map with 700 watersheds. Most of these contained fewer than 25 fires. Consequently, the minimum area threshold was increased in 10,000 hectares increments, up to a value of 40,000 hectares. Along coastal areas, watersheds smaller than 40,000 (a)

\section{Number of fires}

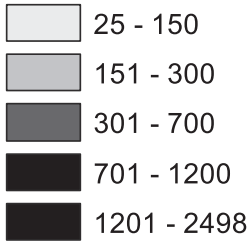

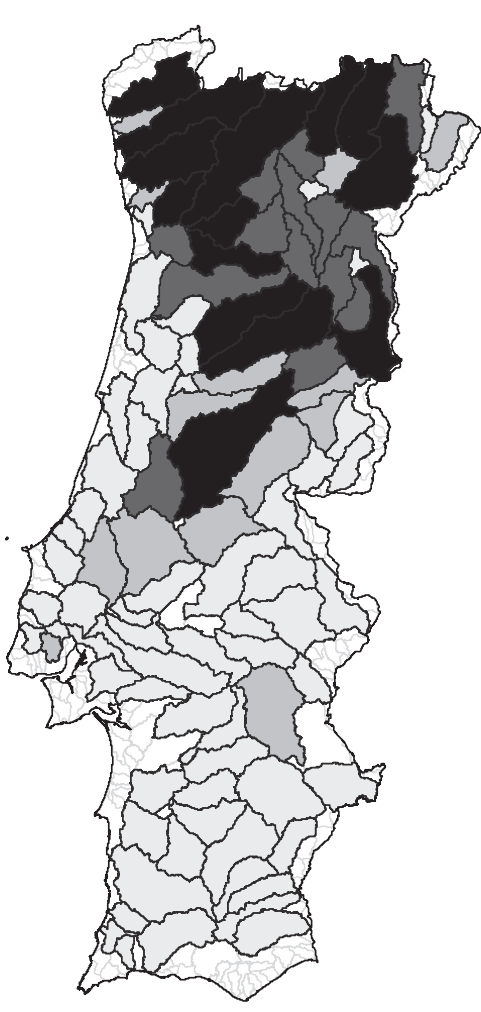

(b)

\section{Area burned (10^2 ha)}

$6-200$

$200-500$

$500-800$

$800-1550$

$1550-4000$

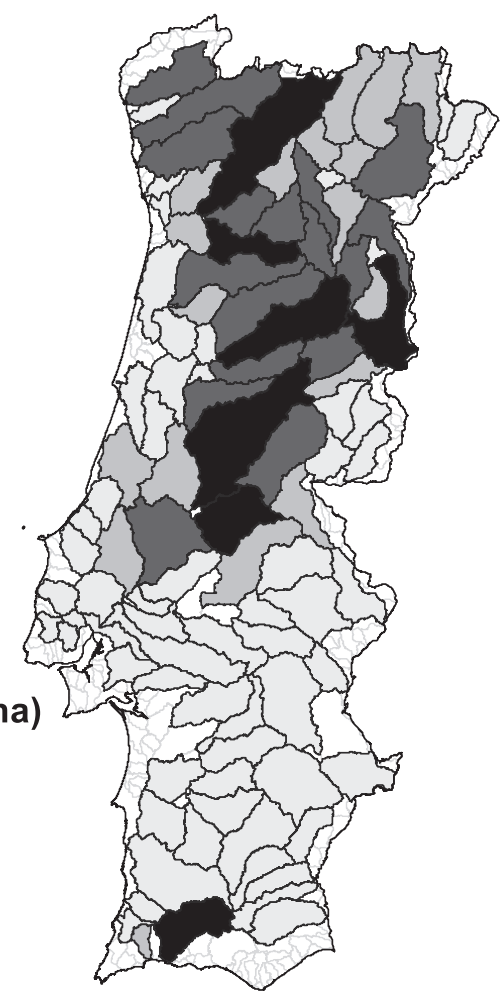

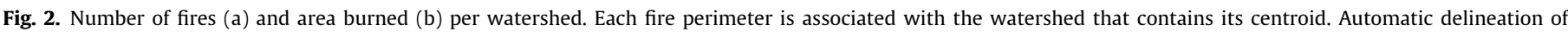

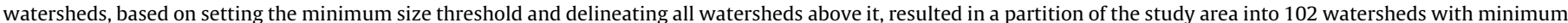

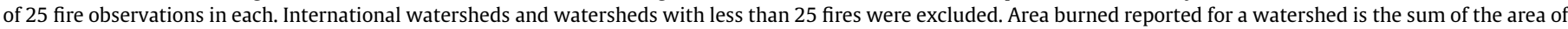
all fire perimeters associated with that watershed. 
hectares were included as long as they contained at least 25 fires. The final map was edited to exclude international watersheds, since we do not have the perimeters of fires occurring in the Spanish portion of these watersheds. This resulted in a total of 102 watersheds, with sizes varying from 10,400 hectares to 277,835 hectares. Each fire was considered belonging to the watershed containing its centroid. The 102 watersheds correspond to $83 \%$ of the Portuguese mainland territory and contain 30,459 fire perimeters, accounting for $90 \%$ of the 1975-2005 overall area burned. The number of fires per watershed ranges from 25 to 2498, while the area burned varies from 500 hectares to 380,900 hectares (Fig. 2).

\subsection{Orientation vs direction}

Circular data refers to data measured on an angular scale, in degrees or radians. There are two kinds of circular data, vectorial (directional) and axial (orientational) circular data. Vectorial data consists of a directed line where both the departure point and direction of movement are known, e.g., the vanishing directions of homing pigeons. Axial data consists of an axis or undirected line, where either end of the line can be taken as the direction of movement, such as a fracture in a rock exposure (Fisher, 1993).

The analysis of circular data requires the definition of an origin, and a sense of rotation - clockwise or counterclockwise (Jammalamadaka and Sengupta, 2001). In this work we computed the orientation of each watershed and fire event. These orientations correspond to axial data, since we lack information on ignition points or the actual fire spread direction. We considered true north $(\mathrm{N})$ as the origin and measured orientations clockwise.

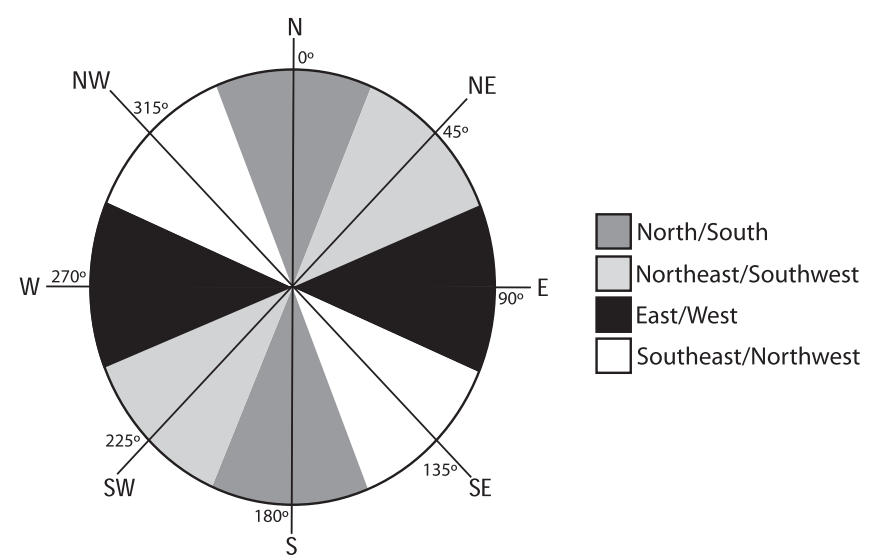

Fig. 3. Classification of axial data in terms of compass orientation. For each fire and watershed perimeter an orientation value, $\theta_{o r}$, is calculated. Orientation values range between $0^{\circ}$ and $180^{\circ}$ and were classified into compass classification as a function of $\theta_{\text {or }}$ as follows: N/S $\left.\left.\Leftrightarrow \theta_{o r} \in[0 ; 22.5] \wedge \theta_{o r} \in\right] 157.5 ; 180\right] ; \quad N E /$ $\left.\left.\left.\left.\left.\left.S W \Leftrightarrow \theta_{o r} \in\right] 22.5 ; 67.5\right] ; \mathrm{E} / \mathrm{W} \Leftrightarrow \theta_{o r} \in\right] 67.5 ; 112.5\right] ; \mathrm{SE} / \mathrm{NW} \Leftrightarrow \theta_{o r} \in\right] 112.5 ; 157.5\right]$. Different shades of grey distinguish the range of the intervals described above.

Given that all orientations are axial, it follows that $0^{\circ}$ (North, N) is equivalent to $180^{\circ}$ (South, S) (Fig. 3). For the sake of simplicity, we shall refer to axial measurements in the compass classifications: N/S, NE/SW, E/W and SE/NW, which can be regarded as equivalent to the orientations $\mathrm{S} / \mathrm{N}, \mathrm{SW} / \mathrm{NE}, \mathrm{W} / \mathrm{E}$ and $\mathrm{NW} / \mathrm{SE}$, respectively.

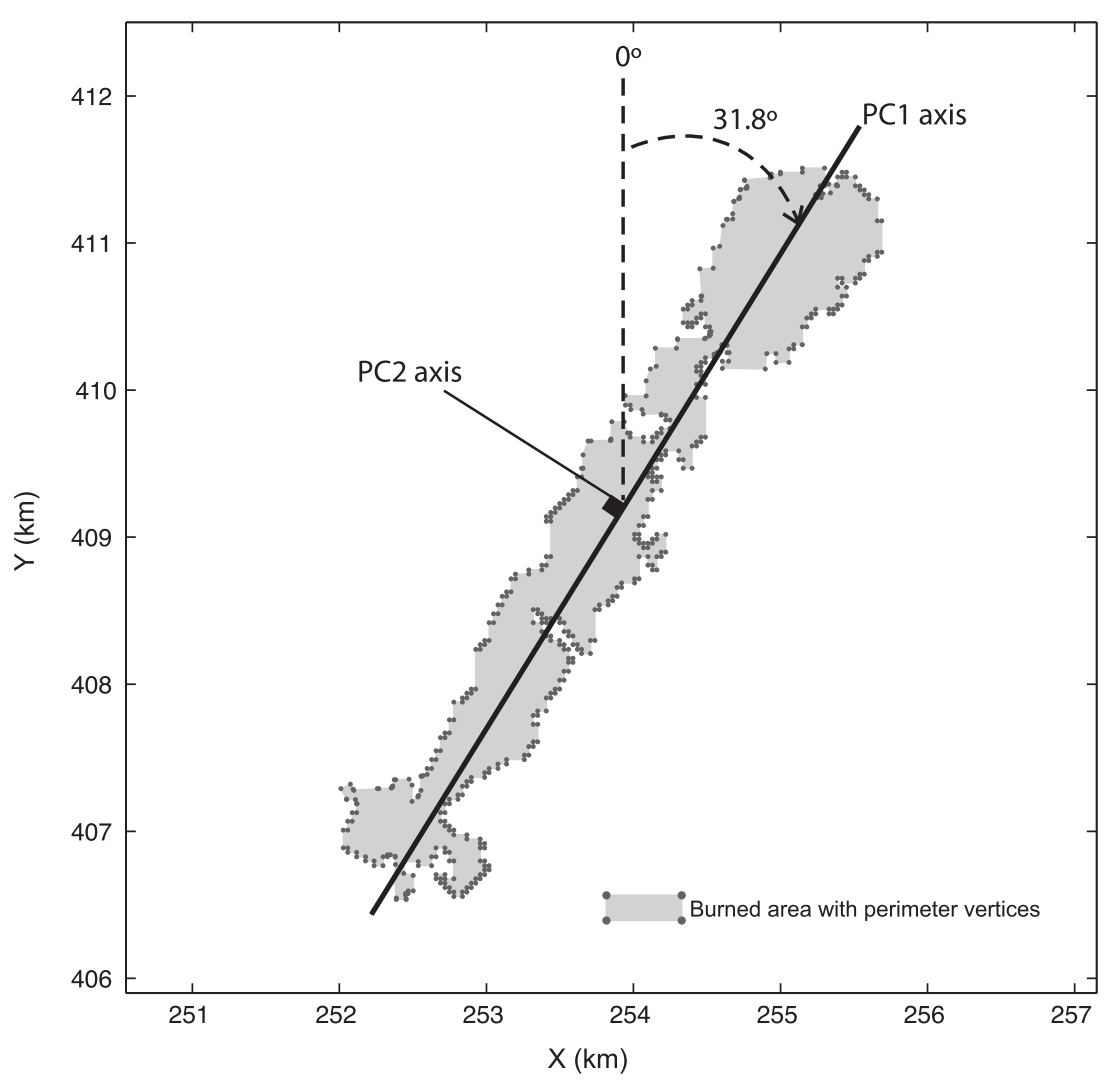

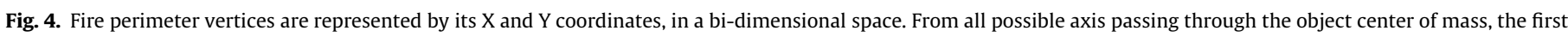

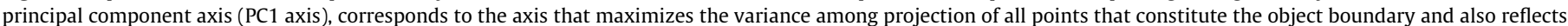

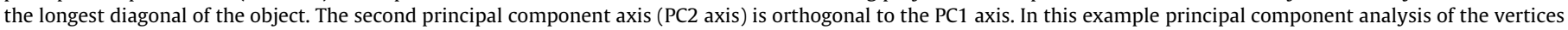
resulted in a PC1 axis with NE/SW (31.8 $)$ orientation. This orientation is measured considering True North as $0^{\circ}$ and rotating clockwise. 


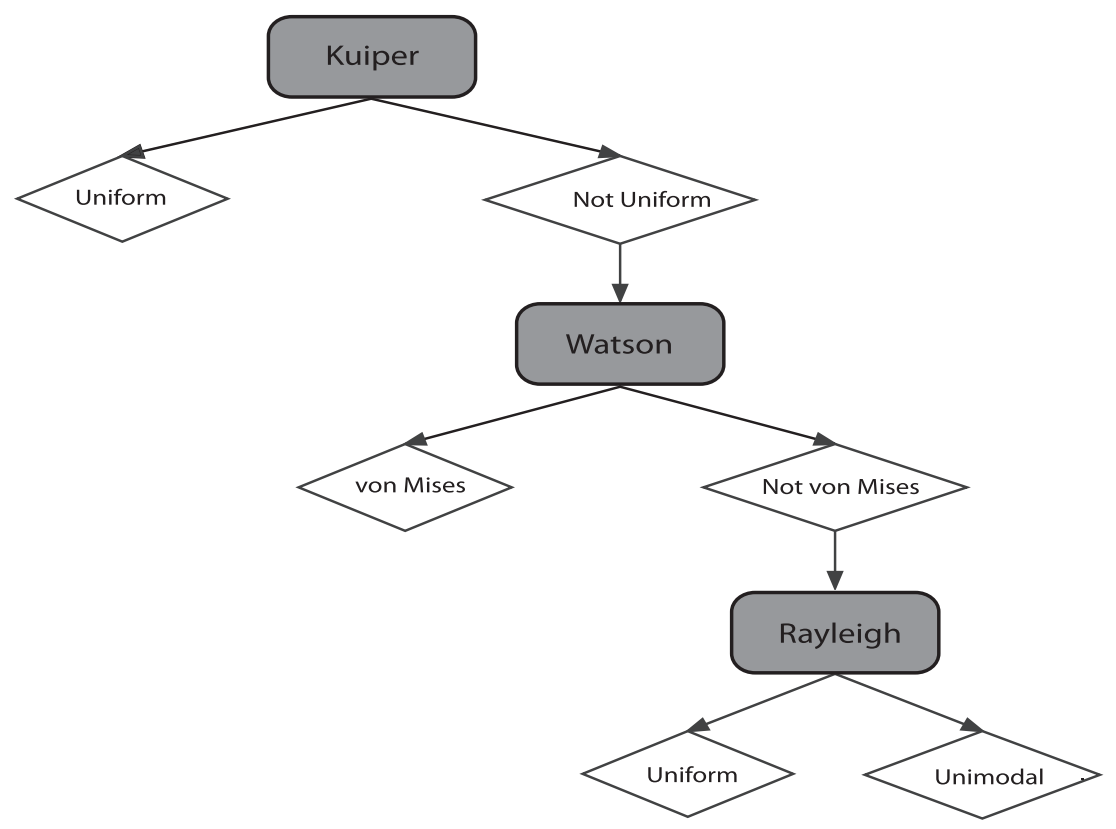

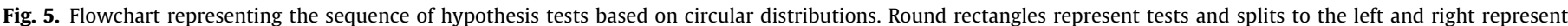

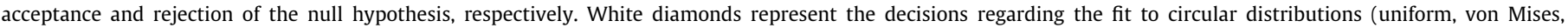
unimodal) at a significance level of $5 \%$.

\subsection{Fire and watershed perimeter orientations}

We used principal component analysis (PCA) (Jolliffe, 2002) to determine the orientation of fire and watershed perimeters, following the approach proposed by Luo (1998). Each object (fire or watershed) boundary vertex corresponds to a point in a bi-dimensional space defined by its $(\mathrm{X}, \mathrm{Y})$ geographical coordinates. The first principal component (PC1) corresponds to an axis in this bi-dimensional space that passes through the object's center of mass and onto which all points are projected. The orientation of this axis maximizes the variance of the projected boundary points, reflecting the length of the object's longest diagonal, and is taken as the object's orientation (Fig. 4).

Object orientation obtained by PCA is less sensitive to boundary details, including inaccuracies, than alternative methods for orientation analysis (Luo, 1998). This is advantageous in our case, since fire boundaries have different levels of detail, depending on whether they result from automatic image classification, or from post-classification manual boundary editing. For a detailed description of a four-step algorithm to compute orientation by principal component analysis see Luo (1998), pp. 131-136. For the purpose of the present work, this algorithm was implemented in Matlab using the built-in princomp function (MathWorks, 2008).

\subsection{Circular statistics analysis}

We conducted a sequence of hypothesis tests - Kuiper's, Watson's and Rayleigh's tests - that investigate the distribution of the population of fire perimeter orientations in each watershed (Fig. 5). These three tests can assess the evidence for a uniform, von Mises and unimodal distribution, respectively.

The circular uniform distribution plays a central role in circular statistics because it represents the absence of a preferred direction, i.e., all directions are equally probable. The von Mises distribution, is the circular analog to the Normal distribution of linear statistics (Davis, 1986). It has two parameters, the first of which defines the location of the reference direction of the distribution (mean direction), while the second parameter defines the scatter about that location and is called concentration $(k)$. The von Mises distribution is symmetric around the mean and increasing $\mathrm{k}$ corresponds to increasing concentration around the mean direction. As $k$ approaches zero the von Mises distribution tends toward the circular uniform distribution (Fisher, 1993).

If the data fit neither a von Mises, nor a uniform distribution, it may still contain a single mode, thus following a unimodal distribution (Fisher, 1993). In this case, although it is not possible to identify the actual distribution, the presence of a mode not only indicates a preferred orientation in the sample, but also enables the use of non-parametric methods to estimate a mean direction with a confidence interval.

Fig. 5 represents the sequence of hypothesis tests performed in this analysis. The Kuiper test is an omnibus test, meaning it tests the hypothesis of the sample following a uniform distribution, against any alternative distribution. If the null hypothesis is rejected, then there is evidence against uniformity and the possibility that the data fit the von Mises distribution is tested. The goodness of fit of the von Mises model can be formally assessed using Watson's test (Fisher, 1993). The null hypothesis in this test is that the data are drawn from a von Mises distribution, against the alternative that they are not drawn from a von Mises distribution. Rejection of the null hypothesis in the Watson's test, leads to rejecting the hypothesis that the data fits a von Mises model. The next step is to determine whether the data presents a single modal direction, using Rayleigh's test, where the alternative hypothesis is unimodality (Fisher, 1993).

For each watershed for which there is evidence of a preferred fire perimeter orientation (von Mises or unimodal), we calculated the circular mean (Fisher, 1993; Otieno and Anderson-Cook, 2006), its confidence interval, and circular variance. The circular mean, denoted by $\bar{\theta}$, is computed from:

$\cos \bar{\theta}=\frac{C}{R} \quad$ and $\quad \sin \bar{\theta}=\frac{S}{R}$

where,

$C=\sum_{i=1}^{n} \cos \theta_{i}, \quad S=\sum_{i=1}^{n} \sin \theta_{i}$ 
$R^{2}=C^{2}+S^{2}$

The circular variance varies between zero and one and its interpretation is similar to variance in linear data, the smaller the value of circular variance, the more concentrated is the distribution. Circular variance is defined as:

$V=1-\bar{R}$

where $\bar{R}$ is the mean resultant length associated with the mean orientation $\bar{\theta}$, and is defined by:

$\bar{R}=\frac{R}{n}$

where, $n$ is the number of observations and $R$ is defined by Eq. 3 .

Confidence intervals for the circular mean fire orientation were computed in two ways, depending on whether the goodness of fit tests indicated a von Mises distribution or a unimodal distribution for the fire orientations within the watershed. A parametric approach was used if the fire orientations had a von Mises distribution, and a non-parametric approach was used if only a unimodal distribution was suggested by the goodness of fit tests (Fisher, 1993).

The 95\% confidence intervals for the mean fire orientation in each watershed were used to formally assess alignment between mean fire orientation in a watershed and the orientation of the watershed itself. Alignment is considered to occur when the watershed orientation is contained in the mean fire orientation confidence interval (Rothermel, 2004). This definition of alignment is sensitive to the number of observations in each watershed. Therefore, as an alternative measure of similarity between fire and watershed orientation, we identified watersheds where mean fire orientation was within $\pm 15^{\circ}$ of watershed orientation. To evaluate the influence of major watershed orientation on fire perimeter mean orientation we calculated the circular correlation between watershed orientation and mean fire orientation (Fisher, 1993). Airflow is guided by topographic features, such as mountains or valleys, establishing local wind direction (Schroeder and Buck, 1970). Alignment between fire orientation and the watershed orientation may be indicative of watersheds where topography determines directional orographic alignment of winds and consequently, wildfires (Schroeder and Buck, 1970; Pyne et al., 1996).

We hypothesized that fire orientation patterns may differ in response to distinct synoptic weather patterns. We tested this hypothesis using two alternative partitions of the original data. In the first approach,we compared fire orientations between mild and severe fire years, using total annual area burned as proxy for fire weather severity (Nunes et al., 2005; Pereira et al., 2005; Trigo et al., 2006; Syphard et al., 2011). We used the 10 years with higher area burned and the 10 years with lower area burned, under the assumption that the two samples are drawn from distinct populations. This analysis was performed considering watersheds with at least 25 fire observations in both time periods, which corresponds to 36 of the 102 watersheds in the study area. In the second approach, we compared individual fire orientations between all the fires with area burned below 100 hectares (small fires) and area burned above 1000 hectares (large fires), using fire size as a proxy for the atypical meteorological conditions conducive for days of extensive area burned (Pereira et al., 2005; Hoinka et al., 2009).

The statistical comparison between the high and low area burned data in each watershed, was done using the WatsonWheeler test which compares two populations to determine if their distributions are identical (Fisher, 1993). This is a non-parametric test, with the null hypothesis stating that the two populations are drawn from identical distributions (Fisher, 1993). The same test was used to compare small and large fires nationally, since the small number of fires larger than 1000 hectares precluded a watershed-level analysis.

All statistical analyses were performed with Oriana (Kovach, 2003), with the exception of the non-parametric confidence intervals, which were computed in Matlab (MathWorks, 2008). All formal hypothesis tests were conducted using a $5 \%$ significance level.

\section{Results}

Analysis of fire perimeters over the 31-year dataset showed that, of the 102 watersheds in the study area, 53 watersheds displayed a preferred fire orientation, out of which 41 watersheds fit a von Mises distribution, whilst 12 watersheds followed a unimodal distribution (Fig. 6). Forty-eight watersheds followed a uniform distribution. For one watershed no conclusive results were attained regarding its fire orientation distribution. However, this watershed only accounts for less than $0.5 \%$ of the study area and of the overall area burned.

Watersheds where fires display a uniform distribution of fire orientation, mostly found along the southern half of the country, represent $38 \%$ of the study area, and account for $16 \%$ of overall area burned. Watersheds with von Mises and unimodal fire orientation distributions are mostly located in northern and central Portugal and represent $86 \%$ of the overall area burned, while covering $61 \%$ of the study area. Variances of fire orientations range from 0.25 to 0.48 , and watersheds in the northern part of the country present higher dispersion around the mean fire orientation (Fig. 6).

The circular mean orientation was computed for watersheds where fires display preferential orientation. Compass classification of mean fire orientation shows two distinct clusters in central Portugal, with NE/SW and SE/NW orientations (Fig. 6). These two clusters account for around $65 \%$ of total area burned in the 31-year dataset (Fig. 7). All watersheds aligned NE/SW occur in the northern half of the study area, while the remaining orientations are associated with watersheds, either clustered or isolated, but distributed throughout the entire study area. There is also a group of watersheds with E/W orientation in northeastern Portugal.

Major topographic orientation of each watershed varies throughout the study area, with clusters of NE/SW and SE/NW orientation in the center and northwest regions, $\mathrm{N} / \mathrm{S}$ clusters along the coast and northeastern border with Spain, and E/W clusters throughout the entire study area (Fig. 8). Comparison between fire and watershed orientation shows that while fire orientation shows two important clusters, with NE/SW and SE/NW orientations (Fig. 6), watershed orientation is more variable (Fig. 8).

From a total of 53 watersheds evidencing preferential fire orientation, only eight display a watershed orientation that is contained within the mean fire orientation confidence interval, indicating strong alignment between watershed orientation and fire orientation in these eight watersheds. Following the alternative criterion for topographic alignment resulted in four more watersheds with evidence of mean fire-watershed alignment. The circular-circular correlation coefficient between watershed orientation and mean fire orientation per watershed has a value of 0.208 , suggesting a weak relationship between major watershed orientation and corresponding fires.

The Watson-Wheeler test did not indicate that fires occurring in the 10 years with highest area burned and fires occurring in the 10 years with the lowest area burned had differing distributions of fire perimeter orientation. For only one of the 36 watersheds analyzed, was there a significant difference $(\alpha=0.05)$. This suggests that during severe fire weather years, although total area burned increases, the orientations of fire perimeters remain consistent with those observed during moderate and mild fire seasons. 
(a)

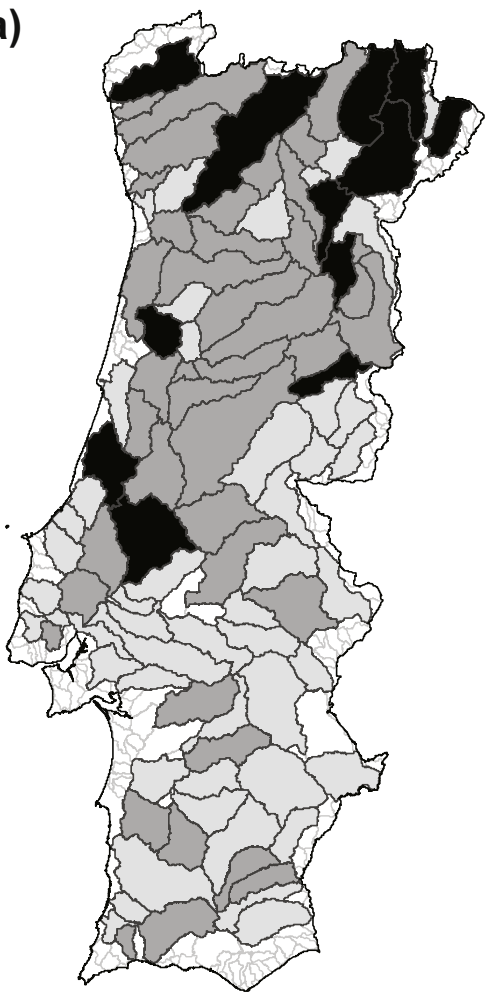

Circular distributions

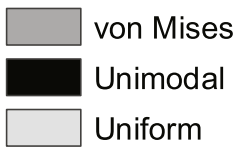

(b)

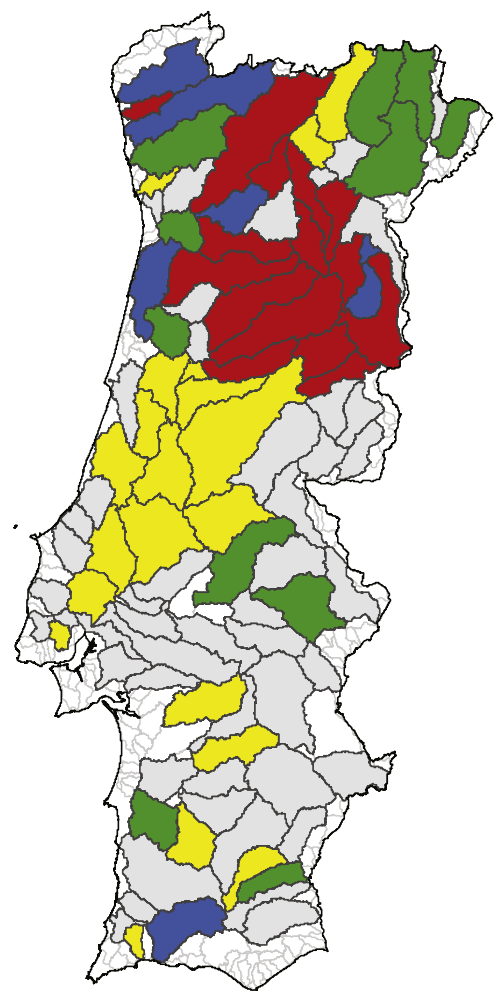

Mean fire orientation

\begin{tabular}{l|l}
\hline E/W \\
N/S \\
NE/SW \\
SE/NW \\
\hline No preferred orientation
\end{tabular}

(c)
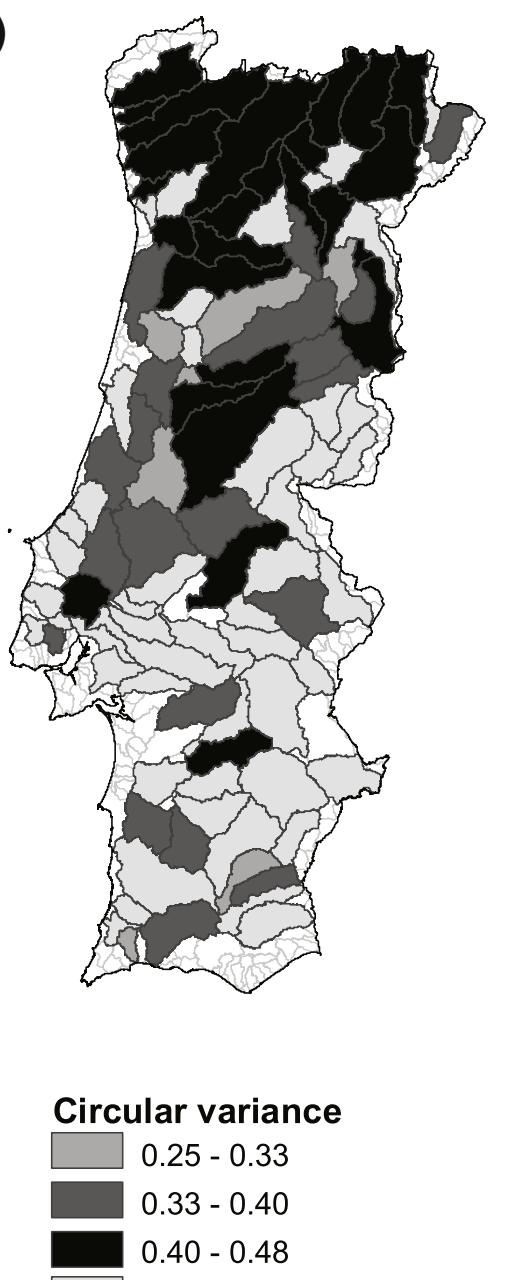

No preferred orientation

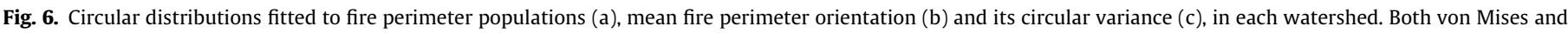

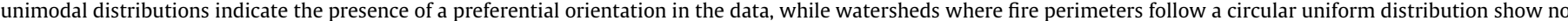

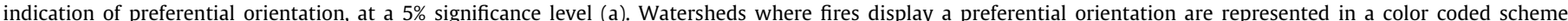

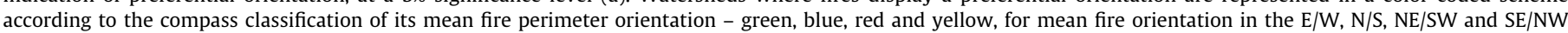

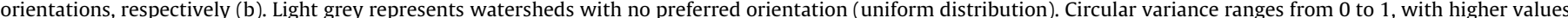

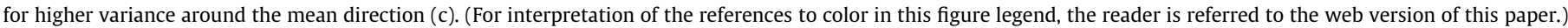

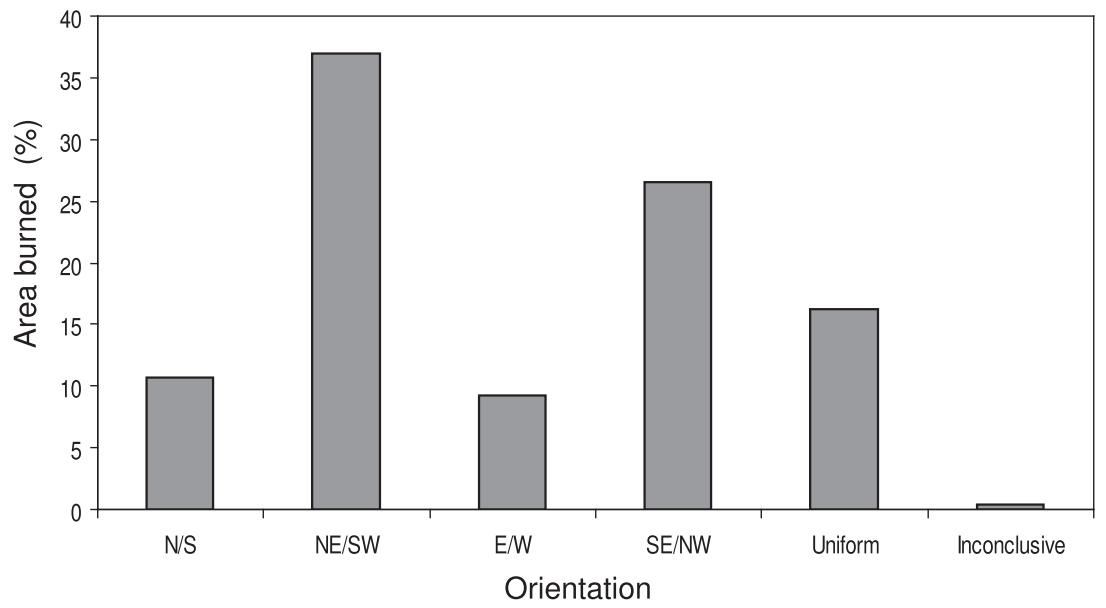

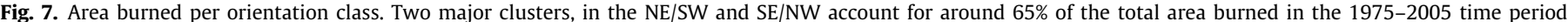

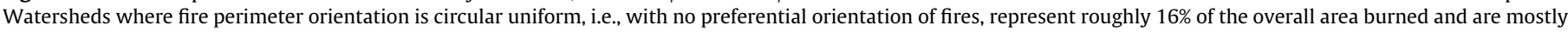
located in the southern portion of the study area. 
(a)
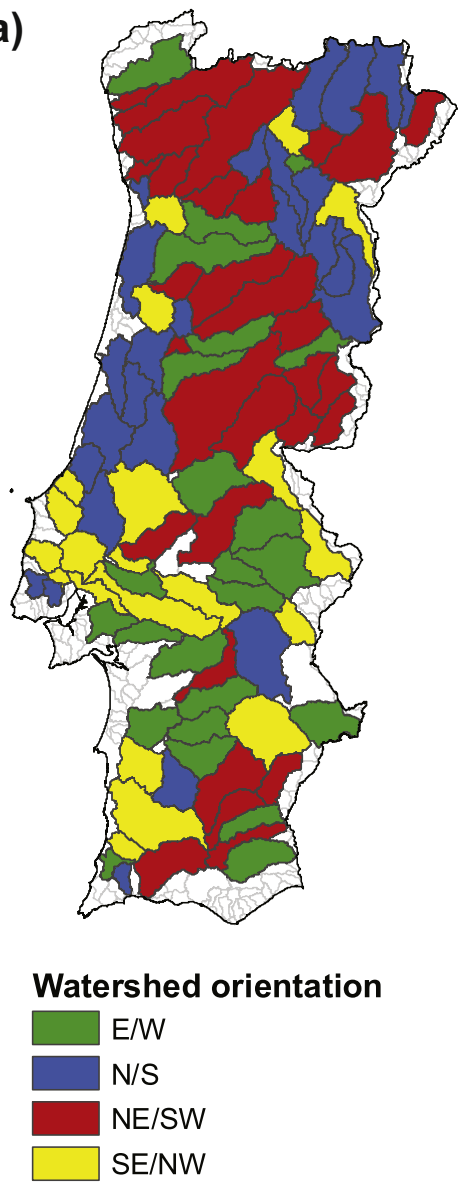

(b)

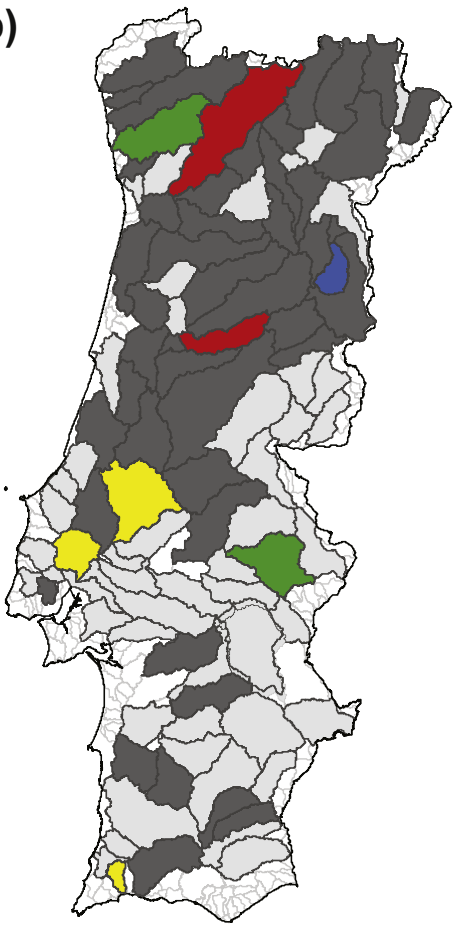

95\% Cl watershed-fire alignment

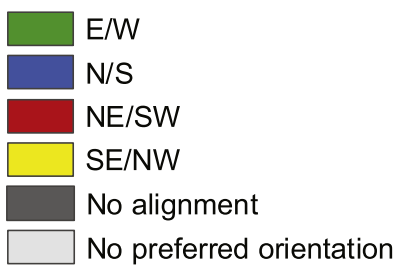

(c)

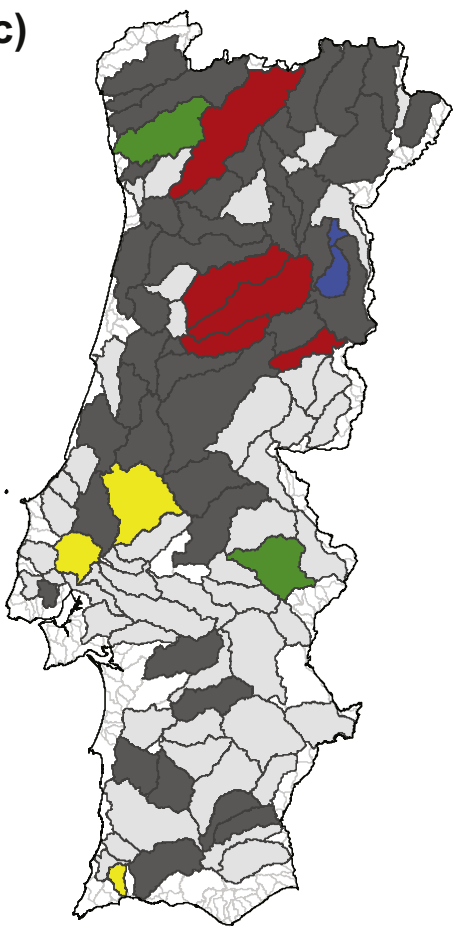

Watershed based fire alignment
E/W
N/S
NE/SW
SE/NW
No alignment
No preferred orientation

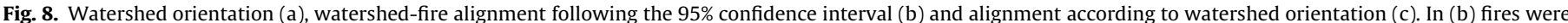

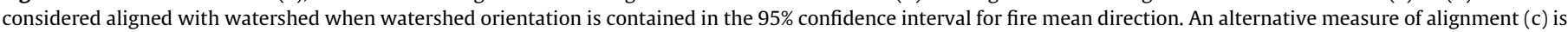

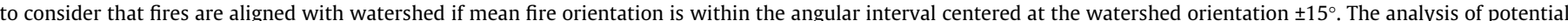

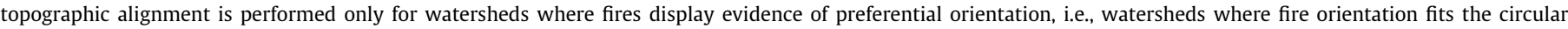
uniform distribution were excluded.

Results for the comparison between small and large individual fires also found little evidence of differing orientations ( $p=0.69$ ).

\section{Discussion and conclusions}

The primary objective of this work was to determine whether fires display geographical orientation patterns, at the watershed scale. A secondary objective was to analyze the relationship between the orientation of fires in a watershed and the orientation of the watershed itself. We also investigated the hypothesis that fire orientation patterns would vary between low and high area burned fire seasons and between small and large fires.

Our analysis suggests that orientation patterns are similar during mild and severe fire seasons and also small ( $\leqslant 100$ hectares) and large ( $\geqslant 1000$ hectares) fires have similar orientations nationally. However, these analyses had two underlying assumptions: total area burned in each year and fire size can be used as proxies for severe fire weather, which primarily determines the occurrence of the majority of area burned in each fire season. This may not be the case; and perhaps a more appropriate delineation to study the effects of fire weather on fire perimeter orientation would focus on comparing the orientation of fires that occurred during days of extensive area burned with fires occurring under milder weather conditions (Pereira et al., 2005; Carvalho et al., 2008). This was not done in this study because we lack information regarding the date of ignition and duration of individual fires.

The circular statistics analysis showed that $84 \%$ of the area burned between 1975 and 2005 is located in watersheds where fires display preferential orientation. This is a remarkable result, considering the heterogeneity of land cover, topography and infrastructure networks across these watersheds, and the role of fire suppression activities. In southern Portugal only a few watersheds display non-uniform fire orientation, but this region corresponds to a small fraction of the total number of fires and area burned. Gently rolling terrain, without very prominent topographic features, relatively homogeneous land cover, and a prevalence of agricultural land management fires, typically set under mild weather conditions, may account for the lack of preferred orientation of fire perimeters.

Two large clusters of watersheds with preferentially-oriented fires are found in central Portugal. Fire orientation is typically $\mathrm{NE} / \mathrm{SW}$ in the northernmost cluster (red), and SE/NW in the southernmost cluster (yellow). Together, these two clusters represent $65 \%$ of overall area burned and contain many of the largest fires recorded during the study period. The location and geographical extent of these clusters is suggestive of a broader scale, climatic determinant, rather than finer scale topographic control. 
This is particularly true, considering that Pereira et al. (2005) identified synoptic patterns of severe fire weather which, although relatively rare, are responsible for most of the area burned in Portugal. The wind field composite for the $10 \%$ highest area burned days over the period 1980-2000 clearly shows a north-easterly component that may influence fire orientation in the northernmost (red) watershed cluster. However, the spatial resolution of that analysis is too coarse to elucidate finer scale wind flow patterns.

Hoinka et al. (2009) analyzed relationships between regional scale weather patterns and wildfires in central Portugal, namely the role of the Iberian thermal low (Hoinka and Castro, 2003; Hoinka et al., 2007). They showed that previously to days with extensive area burned, the atmospheric flow above Portugal is from the north, turning to easterly on the severe fire day, and to south-easterly afterwards. Analysis of the relationship between the Iberian thermal low and area burned showed that peak fire incidence was observed up to three days after the appearance of a thermal low. Hoinka et al. (2009) interpreted this observation as indicating that during a few days preceding a large area burned episode, heated air is transported westward from central Iberia towards Portugal. They also showed that during severe fire days and at $10 \mathrm{~m}$ above sea level, wind flow is from the northeast in the northern half of Portugal and from east-southeast in the southern half of Portugal, in agreement with the fire orientation patterns detected in this study.

Alignment of watershed orientation and mean fire orientation occurs in a small number of watersheds scattered throughout the study area. Directional wind channelling by topography may contribute towards coincidence of main valley, wind, and fire orientation. It occurs when a large drainage diverts some of the incoming wind flow, sending it in a direction parallel to the drainage (Pyne et al., 1996). Nevertheless, topographic wind channeling cannot be ruled out where coincident orientation of fire perimeters and the main drainage is absent, because this alignment may occur within second order basins, which was not tested in this work.

While we did not formally assess differences in fire orientation in relation with land cover, we believe that land cover is unlikely to be responsible for the patterns of fire perimeter orientation found in this study. Our results show that fire perimeter orientations remains consistent across watersheds with widely variable proportions of major land cover types. It is also reasonable to assume that fire suppression does not alter fire perimeter orientation within or among watersheds. Historically, fire suppression in Portugal has focused on the vicinity of human settlements and infrastructures and therefore emphasize protecting these areas from fire, with considerable less amount of suppression effort applied directly to containing the flame front while it spreads through wildland fuels (Beighley and Quesinberry, 2004; AFN, 2006).

The geographical pattern of clustering detected in fire perimeter orientation and the heterogeneous relationship between mean fire orientation and watershed orientation highlight the need to regionalize the design of fuel break networks and include sitespecific information to optimize their effectiveness. Locating fuel breaks along the main ridge or main riparian area of a watershed may not be the best option. On a more local scale, the identification of potential orographic channelling has direct implications in terms of fire risk and management, because it creates conditions for potentially high intensity fires.

The fact that more than half of the overall area burned displays non-random orientation, which remains consistent between mild and severe fire seasons, indicates that the spatial patterns identified are indeed useful to support regional-scale planning of fuel break networks. Of course, much more remains to be done concerning the complex, finer-scale interactions between wind and topography and their effects on fire behavior (Linn et al., 2007; Sharples, 2008). Further clarification of regional fire spread direc- tions will be gathered from analysis of smoke plumes and time series of active fire, observed with satellite imagery. Future work should focus on analysis of multi-annual meteorological data from the Fifth-generation Penn State/NCAR Mesoscale Model (MM5) (Grell et al., 1994) to serve as regional wind input to topographic exposure/deflection indexes, and for mapping dynamic topographic channelling. This will highlight the relative influence of weather and topography as determinants of regional patterns of fire orientation.

\section{Acknowledgements}

Thanks are due to Nuno Lemos for his help with the programming described in Section 2.4 and the two anonymous reviewers who provided constructive comments on an early version of the manuscript. This paper was supported by the Fundação para a Ciência e Tecnologia Ph.D. Grant SFRH/BD/40398/2007. JMCP participated in this research under the framework of research projects "Forest fire under climate, social and economic changes in Europe, the Mediterranean and other fire-affected areas of the world (FUME)", EC FP7 Grant Agreement No. 243888, and "Fire- LandAtmoshere Inter-Relationships: understanding processes to predict wildfire regimes in Portugal" (FLAIR), PTDC/AAC - AMB/104702/ 2008.

\section{References}

AFN, 2006. Plano Nacional da Defesa da Floresta Contra Incêndios. Autoridade Florestal Nacional.

AFN, 2007. Inventário Florestal Nacional 2005-2006. Autoridade Florestal Nacional Agee, J., Skinner, C., 2005. Basic principles of forest reduction treatments. Forest Ecology and Management 211, 83-96.

Beighley, M., Quesinberry, M., 2004. Final Report Portugal Wildland Fire Technical Exchange Project. USDA Forest Service.

Bergeron, Y., Gauthier, S., Flannigan, M., Kafka, V., 2004. Fire regimes at the transition between mixedwood and coniferous boreal forest in Northwestern Quebec. Ecology 85 (7), 1916-1932.

Carvalho, A., Flannigan, M., Logan, K., Miranda, A., Borrego, C., 2008. Fire activity in portugal and its relationship to weather and the canadian fire weather index system. International Journal of Wildland Fire 17, 328-338.

CNR, 2005. Orientações estratégicas para a recuperação das áreas ardidas em 2003 e 2004. Ministério da Agricultura do Desenvolvimento Rural e das Florestas.

Collins, B., Stephens, S., Moghaddas, J., Battles, J., 2010. Challenges and approaches in planning fuel treatments across fire-excluded forested landscapes. Journal of Forestry, January/February.

Davis, J.C., 1986. Statistics and data analysis in geology, second ed. John Wiley \& Sons.

ESRI, 2009. ArcMap 9.2. Environmental Systems Resource Institute, Redlands, California.

Farr, T., Rosen, P., Caro, E., Crippen, R., Duren, R., Hensley, S., Kobrick, M., Paller, M., Rodriguez, E., Roth, L., Seal, D., Shaffer, S., Shimada, J., Umland, J., Werner, M., Oskin, M., Burbank, D., Douglas, A., 2007. The shuttle radar topography mission. Reviews of Geophysics 45 (RG2004).

Finney, M., 2001. Design of regular landscape fuel treatment patterns for modifying fire growth and behavior. Forest Science 47 (2), 219-228.

Finney, M., 2004. Landscape fire simulation and fuel treatment optimization. In: Hayes, J., Ager, A., Barbour, J. (Eds.), Methods for Integrated Modeling of Landscape Change. Interior Northwest Landscape Analysis System. Chp. 9 General Technical Report PNW-GTR-610. USDA Forest Service, Pacific Northwest Research Station, Portland, Oregon, pp. 117-131.

Finney, M., 2007. A computational method for optimizing fuel treatment options. In: Andrews, P., Butler, B. (Eds.), Fuels management: How to measure success: Conference Proceedings 28-30 March 2006 Portland Oregon. USDA Forest Service. Rocky Mountains Research Station, Fort Collins, Colorado, pp. 107-123.

Finney, M., Seli, R., McHugh, C., Ager, A., Bahro, B., Agee, J., 2007. Simulation of longterm landscape-level fuel treatments on large wildfires. International Journal of Wildland Fire 16, 712-727.

Fisher, N.I., 1993. Statistical Analysis of Circular Data. Cambridge University Press, New York, NY, USA

Grell, G., Dudhia, J., Stauffer, D., 1994. In: A description of the Fifth-generation Penn State/NCAR Mesoscale Model (MM5). NCAR Tech Note TN-398 + STR, p. 122.

Haydon, D.T., Friar, J.K., Pianka, E.R., 2000. Fire-driven dynamic mosaics in the Great Victoria Desert, Australia - 1. fire geometry. Landscape Ecology 15 (4), 373-381.

Hoinka, K., Carvalho, A., Miranda, A., 2009. Regional-scale weather patterns and wildland fires in Central Portugal. International Journal of Wildland Fire 18, 36-49. 
Hoinka, K., Castro, M.D., 2003. The Iberian Peninsula thermal low. Quarterly Journal of the Royal Meteorological Society 129 (590), 1491-1511.

Hoinka, K., Gaertner, M., Castro, M.D., 2007. Iberian thermal lows in a changed climate. Quarterly Journal of the Royal Meteorological Society 133 (626) 1113-1126.

Jammalamadaka, S.R., Sengupta, A., 2001. Topics in Circular Statistics. World Scientific, Singapore, River Edge, NJ.

Jolliffe, I., 2002. Principal Component Analysis. Springer.

Kovach, W., 2003. Oriana. Circular Statistics for Windows. Version 2. Kovach Computing Services.

Linn, R., Winterkamp, J., Edminster, C., Colman, J., Smith, W., 2007. Coupled influences of topography and wind on wildland fire behaviour. Internationa Journal of Wildland Fire 16, 183-195.

Loehle, C., 2004. Applying landscape principles to fire hazard reduction. Forest Ecology and Management 198, 261-267.

Luo, D., 1998. Pattern Recognition and Image Processing. Horwood Publishing.

Miranda, P., Coelho, F., Tomé, A., Valente, M., Carvalho, A., Pires, C., Pires, H., Pires, V., Ramalho, C., 2002. 20th century portuguese climate and climate scenario. In: Santos, F., Forbes, K., Moita, R. (Eds.), Climate Change in Portugal: Scenarios, Impacts and Adaptation Measures (SIAM Project). Gradiva, Lisboa, pp. 23-83.

Nunes, M., Vasconcelos, M., Pereira, J., Dasgupta, N., Alldredge, R., Rego, F., 2005. Land cover type and fire in portugal: do fires burn land cover selectively? Landscape Ecology 20 (6), 661-673.

Otieno, B.S., Anderson-Cook, C.M., 2006. Measures of preferred direction for environmental and ecological circular data. Environmental and Ecological Statistics 13 (3), 311-324.

Parisien, M.A., Peters, V.S., Wang, Y.H., Little, J.M., Bosch, E.M., Stocks, B.J., 2006 Spatial patterns of forest fires in Canada, 1980-1999. International Journal of Wildland Fire 15 (3), 361-374.

Pereira, J.M.C., Carreiras, J.M.B., Silva, J.M.N., Vasconcelos, M.J., 2006. Alguns conceitos sobre fogos rurais em Portugal. In: Pereira, J.S., Pereira, J.M.C., Rego F., Silva, J.M.N., Silva, T.P. (Eds.), Incêndios Florestais em Portugal Caracterização, Impactes e Prevenção. ISA Press, Lisboa, pp. 133-162.
Pereira, M., Trigo, R., da Câmara, C., Pereira, J., Leite, S., 2005. Synoptic patterns associated with large summer forest fires in Portugal. Agricultural and Forest Meteorology 129 (1-2), 11-25.

Pyne, S., Andrews, P., Raven, R., 1996. Introduction to Wildland Fire, second ed. John Wiley \& Sons, New York.

Reinhardt, E., Keane, R., Calkin, D., Cohen, J., 2008. Objectives and considerations for wildland fuel treatments in forested ecosystems of the interior western United States. Forest Ecology and Management 256, 1997-2006.

Ribeiro, O., Lautensach, H., Daveau, S., 1987. Geografia de Portugal. A posição geográfica e o território. Edições João Sá da Costa, Lisboa, Portugal.

Rothermel, B.B., 2004. Migratory success of juveniles: a potential constraint on connectivity for pond-breeding amphibians. Ecological Applications 14 (5), $1535-1546$.

Schmidt, D., Taylor, A., Skinner, C., 2008. The influence of fuel treatments and landscape arrangement on simulated fire behavior, Southern Cascade range, California. Forest Ecology and Management 255, 3170-3184.

Schroeder, M., Buck, C., 1970. Fire weather. In: Andrews, P., Butler, B. (Eds.), Agricultural Handbook 360. US Department of Agriculture, Forest Service, Fort Collins, Colorado, p. 229.

Sharples, J., 2008. Review of formal methodologies for wind-slope correction of wildfire rate of spread. International Journal of Wildland Fire 17, 179-193.

Strahler, A., Strahler, A., 1992. World climates. In: Modern Physical Geography, third ed. Wiley, New York, pp. 162-165.

Syphard, A., Keely, J., Brennan, T., 2011. Comparing the role of fuel breaks across southern California national forests. Forest Ecology and Management 261, 2038-2048.

The MathWorks, I., 2008. Matlab - statistics toolbox, version 7.2. The MathWorks Inc., Natick, Massachussetts. Available from:

Trigo, R., Pereira, J., Pereira, M., Mota, B., Calado, T., Camara, C.D., Santo, F., 2006. Atmospheric conditions associated with the exceptional fire season of 2003 in Portugal. International Journal of Climatology 26 (13), 1741-1758.

Weatherspoon, C., Skinner, C., 1996. Landscape-level strategies for forest fuel management. Sierra Nevada Ecosystem Project: Final Report to Congress 2, 1471-1492. 